\title{
COMPORTAMENTO PRODUTIVO DE CAUPI EM REGIMES IRRIGADO E DE SEQUEIRO EM PETROLINA E JUAZEIRO' ${ }^{1}$
}

\author{
CARLOS ANTÔNIO FERNANDES SANTOS² ${ }^{2}$ FRANCISCO PINHEIRO DE ARAÚJO² e EDUARDO ASSIS MENEZES ${ }^{3}$
}

\begin{abstract}
RESUMO - O caupi (Vigna unguiculata (L.) Walp.) é a cultura de grãos mais importante da região Semi-Árida brasileira. O objetivo deste trabalho foi avaliar a adaptabilidade e a estabilidade produtiva de 18 genótipos de caupi em regimes irrigado e de sequeiro, em quatro anos (1995 a 1998), nos Municípios de Petrolina, PE, e Juazeiro, BA. Os genótipos compuseram dois experimentos repetidos cinco vezes em delineamento de blocos casualizados, com quatro repetições. A produção de grãos foi corrigida por covariância no estande ideal de plantas e submetida a análises estatísticas. A presença de variações na fertilidade do solo, no manejo e no quadro pluviométrico, alterou o comportamento produtivo dos genótipos $(\mathrm{P}<0,01)$. O genótipo Balinha, selecionado e mantido por pequenos produtores, produziu $1.779 \mathrm{~kg} / \mathrm{ha}$ em áreas irrigadas, comportamento, este, superior ou similar ao de cultivares das instituições de pesquisa. Em regime de sequeiro, os resultados indicam genótipos superiores, como a cultivar EPACE 10, com $1.343 \mathrm{~kg} / \mathrm{ha}$ e a linhagem TE 90-178-1F, com $1.176 \mathrm{~kg} / \mathrm{ha}$. A cultivar EPACE 11 apresentou bom comportamento produtivo, tanto em regime de sequeiro como em regime irrigado, com $1.497 \mathrm{~kg} / \mathrm{ha}$. Esses resultados indicam a necessidade do desenvolvimento de genótipos de caupi específicos para diferentes ambientes, com ênfase especial para áreas irrigadas.
\end{abstract}

Termos para indexação: Vigna unguiculata, interação genótipo-ambiente, adaptação, grãos, rendimento.

\section{YIELD PERFORMANCE OF COWPEA GENOTYPES UNDER IRRIGATED AND RAINFED CONDITIONS IN PETROLINA AND JUAZEIRO, BRAZIL}

\begin{abstract}
Cowpea (Vigna unguiculata (L.) Walp.) is the most important grain crop in the Brazilian semi-arid region. The objective of this work was to evaluate eighteen genotypes under irrigated and rainfed conditions in Petrolina, PE, and Juazeiro, BA, Brazil, in the years of 1995, 1996, 1997 and 1998.The experiment consisted of two trials, which were replicated five times in a randomized block design, with four replications. The grain yields corrected to ideal stand by covariance were analyzed by different statistical procedures. Variations in soil fertility, crop management and rainfall average were enough $(\mathrm{P}<0.01)$ to modify the grain yield of the genotypes. The Balinha genotype, selected and maintained by small farmers, showed better yield performance, $1,779 \mathrm{~kg} / \mathrm{ha}$, under irrigation conditions than traditional cultivars recommended by research centers. Under rainfed conditions, the results showed good genotypes, like EPACE 10 cultivar and TE 90-178-1F line, with 1,343 kg/ha and 1,176 kg/ha, respectively. EPACE 11, with 1,497 kg/ha, showed good performance under both conditions. All results showed that it is necessary to develop specific genotypes for different environments and social conditions, with special focus on irrigated conditions.
\end{abstract}

Index terms: Vigna unguiculata, genotype environment interaction, adaptation, grain, yields.

\footnotetext{
${ }^{1}$ Aceito para publicação em 10 de abril de 2000.

${ }^{2}$ Eng. Agrôn., M.Sc., Embrapa-Centro de Pesquisa Agropecuária do Trópico Semi-Árido (CPATSA), Caixa Postal 23, CEP 56300-000 Petrolina, PE. E-mail: cafs@cpatsa.embrapa.br, pinheiro@cpatsa.embrapa.br

${ }^{3}$ Eng. Agrôn., Ph.D., Embrapa-CPATSA.

E-mail: emenezes@cpatsa.embrapa.br
}

\section{INTRODUÇÃO}

O caupi (Vigna unguiculata (L.) Walp.) é a mais importante leguminosa de grãos do Semi-Árido brasileiro, e exerce a função de suprir parte das necessidades protéicas das populações mais carentes da região (Teixeira et al., 1988). 
Esta leguminosa ocupa $60 \%$ das áreas cultivadas com feijão (Phaseolus vulgaris) e caupi no Nordeste do Brasil, e representa 26,8\% da área total plantada com feijão no Brasil (Teixeira et al., 1988), alcançando de $95 \%$ a $100 \%$ do total das áreas plantadas com feijão nos Estados do Maranhão, Piauí, Ceará e Rio Grande do Norte.

Tradicionalmente cultivado em regime de sequeiro, o caupi surge como uma opção para cultivo em regime irrigado no Nordeste. Nessas áreas, é cultivado em sucessão a outra cultura de maior valor econômico, de forma a aproveitar o efeito residual da adubação e uma menor oferta do produto em algumas épocas de entressafra. A área cultivada com caupi nos anos de 1993 a 1996, apenas no Projeto Nilo Coelho, em Petrolina, PE, foi de 3.156 ha/ano, com produtividade de $1.520 \mathrm{~kg} / \mathrm{ha}$ de grãos. As cultivares mais cultivadas no referido projeto são IPA 206, EPACE 10 e Canapu Precoce. Já em áreas de sequeiro a produtividade alcançada pelos agricultores é de $300 \mathrm{~kg} / \mathrm{ha}$ de grãos. As sementes utilizadas nos plantios de sequeiro são, normalmente, genótipos locais, selecionados e mantidos pelos agricultores.

A recomendação de cultivares com base unicamente nas produtividades médias obtidas numa região e extrapoladas para outra pode resultar em produções bem abaixo do esperado, quando cultivadas em outras condições (Duarte \& Zimmermann, 1994). Os efeitos da interação genótipo $\mathrm{x}$ ambiente podem ser resultantes de diferentes fatores, como: condições ambientais, fertilidade do solo, conhecimentos tecnológicos dos produtores, e sistema de manejo adotado. Esses fatores, isoladamente ou em conjunto, podem alterar o comportamento de um genótipo, mesmo numa região de pequena extensão territorial.

Existem inúmeros métodos para estudar a adaptabilidade e estabilidade dos genótipos quando ocorre a interação genótipo $\mathrm{x}$ ambiente, sendo o método proposto por Eberhart \& Russell (1966) o mais usado. Estudos comparativos têm demonstrado a eficiência deste método em relação a outros que utilizam um só parâmetro de avaliação (Duarte \& Zimmermann, 1994).

Cruz \& Regazzi (1994) discutem vários métodos disponíveis para análise do comportamento de genótipos em uma série de ambientes, como os mé- todos que consideram a decomposição da interação genótipo x ambiente, os métodos de regressão linear, e os métodos de regressão linear bi-segmentado. Outras informações desses metodos são também dadas por Vencovsky \& Barriga (1992) e Ramalho (1993).

O presente trabalho teve como objetivo estudar a adaptabilidade e estabilidade de rendimento de cultivares e genótipos de caupi em regime irrigado e de sequeiro.

\section{MATERIAL E MÉTODOS}

Dois experimentos com caupi foram avaliados em regimes irrigado e sequeiro nos Municípios de Petrolina, PE, e Juazeiro, BA. O experimento em regime irrigado, repetido cinco vezes, foi conduzido sempre no segundo semestre dos anos de 1995 e 1997, nas estações experimentais de Bebedouro (EEB), da Embrapa-Centro de Pesquisa Agropecuária do Trópico Semi-Árido (CPATSA), e do IPA (EEI) no Projeto Nilo Coelho, em Petrolina, e de Mandacaru (EEM), em Juazeiro. O experimento em regime de sequeiro, repetido seis vezes, foi sempre conduzido no primeiro semestre dos anos de 1996, 1997 e 1998, nas estações experimentais da Embrapa em Bebedouro (EEB), de Caatinga (EEC) em Petrolina, e de Mandacaru (EEM), em Juazeiro. Os tratamentos foram selecionados entre 50 genótipos, com base em avaliações e seleções anteriores, tanto em regime irrigado como de sequeiro. Alguns tratamentos foram comuns aos experimentos de sequeiro e irrigado, e EPACE 11 e Canapu Precoce foram incluídos em ambos os experimentos dos anos 1997 e 1998.

O sistema de irrigação adotado na EEI foi por aspersão, e nas outras estações foi por infiltração. O solo da EEM é do tipo Vertissolo, e o das outras estações é do tipo Latossolo. O delineamento foi de blocos completos, ao acaso, com quatro repetições. O espaçamento adotado foi de $1,0 \mathrm{~m} \times 0,5 \mathrm{~m}$, com duas plantas/cova; a área total de cada parcela foi de $16 \mathrm{~m}^{2}$, e a área útil foi formada por $6,0 \mathrm{~m}^{2}$. Os tratos culturais consistiram de capinas e pulverizações com inseticidas, sem qualquer tipo de adubação.

Foram avaliadas, na área útil de cada parcela, oito variáveis, a saber: dias para a maturação (DPM), peso de 100 grãos (PCG), produção de grãos (PRO) e número de plantas na maturação, e, por ocasião da caracterização em avaliações anteriores, avaliaram-se as variáveis comprimento da vagem (COV), cor da semente (COS), número de sementes/vagem (NSV) e comprimento da haste principal (CHP). 
Os procedimentos estatísticos adotados consistiram de: análise de variância de cada ambiente, segundo o modelo de blocos ao acaso. Para Cruz \& Regazzi (1994), essa análise é importante, para que se possa avaliar a existência de variabilidade genética entre os genótipos estudados, a precisão relativa de cada experimento, e a homogeneidade das variâncias residuais; e ajuste da produção de grãos (g/parcela) do estande inicial de 24 plantas/parcela, pelo método da covariância. Para Vencovsky \& Barriga (1992), a ocorrência de falhas no estande requer a correção dos dados, de forma que as análises biométricas, os testes de hipóteses, as comparações das médias dos tratamentos e a análise conjunta de experimentos possam ser efetuados. Para esses autores, a simples correção por regra de três deve ser evitada, por apresentar resultados pouco confiáveis.

$\mathrm{O}$ ajuste foi efetuado por um modelo linear, admitindo-se que a variação no rendimento de todos os genótipos possa ser quantificada por um mesmo coeficiente de regressão b (Vencovsky \& Cruz, 1991; Vencovsky \& Barriga, 1992).

Foi realizada a análise conjunta dos experimentos, considerando fixo o efeito dos genótipos e os demais efeitos aleatórios, conforme procedimentos e testes estatísticos apresentados por Cruz \& Regazzi (1994). A análise da estabilidade e adaptabilidade dos genótipos sobre o caráter produção de grãos foi conduzida segundo o método de Eberhart \& Russell (1966). Os conceitos e avaliações envolvidos na interpretação dos parâmetros obtidos nesta análise são os comentados por Cruz \& Regazzi (1994).

Foram realizadas as análises considerando-se os tratamentos comuns dos experimentos conduzidos em 1997 e 1998, em ambos os ambientes, cujo dados referentes à produção foram transformados em raiz quadrada, de forma a homogeneizar a variância residual entre os experimentos e possibilitar a análise conjunta. As análises foram executadas no programa computacional Genes (Cruz, 1997) e no Statistical Analysis System (SAS Institute, 1989).

\section{RESULTADOS E DISCUSSÃO}

Os genótipos que apresentaram haste principal de menor comprimento foram Cana Verde, Vita 3 e IT $85 \mathrm{~F}-2264$, todos avaliados em regime de sequeiro (Tabela 1). Grãos com peso em torno de $19 \mathrm{~g} / 100$ grãos foram observados nos genótipos Canapu Precoce, Vita 3 e EPACE 11, e o menor tamanho de grão foi observado na cultivar BR 17 Gurguéia. Existe a tendência de rejeição dos consumidores do Submédio
São Francisco em relação às cultivares que apresentam grãos de tamanho reduzido, como a cultivar BR 17 Gurguéia. O menor comprimento de vagem foi verificado no genótipo local, Balinha, e na cultivar Cana Verde. Vagem curta ou de tamanho intermediário, como foi apresentada pelo genótipo Balinha, é desejável em áreas irrigadas, porque a possibilidade de contato destas com o solo úmido é menor. Já vagens compridas, como as apresentadas pela cultivar IPA 206, podem tocar o solo com maior freqüência, provocando a deterioração de grãos. Com exceção da cultivar Vita 3, que apresentou grão de cor vermelha, os demais genótipos avaliados apresentaram grãos de cor aceitável pela maioria dos consumidores nordestinos.

Dos genótipos que compuseram os dois experimentos, oito são cultivares lançadas por instituições de pesquisa do Nordeste e Norte do Brasil, dois são oriundos de produtores da região, dois são introduções da Nigéria, e o restante é composto por linhagens desenvolvidas pela Embrapa-Centro de Pesquisa Agropecuária do Meio-Norte (Tabela 1), sendo, portanto, bastante representativos do que vem sendo praticado e desenvolvido no Nordeste.

Os parâmetros de adaptabilidade e estabilidade, estimados segundo método de Eberhart \& Russell (1966) e as estimativas dos quadrados médios dos genótipos, avaliadas em regime irrigado, são apresentados na Tabela 2. Todos os quadrados médios mostraram significância, inclusive quanto à interação genótipo $\mathrm{x}$ ambiente. As principais alterações ocorridas nas áreas onde os experimentos foram conduzidos estão relacionados ao tipo de irrigação e solo. O genótipo local Balinha, coletado entre produtores de Ouricuri, PE, destacou-se por apresentar a maior média, ampla adaptação $\left(\hat{\beta}_{1 \mathrm{i}}=1\right)$ e boa previsibilidade produtiva ( $\hat{\sigma}_{\mathrm{di}}^{2}=0$ ), superando estatisticamente a produção das cultivares EPACE 11 e Santo Inácio (Tabela 2). Já a cultivar EPACE 10, apesar de apresentar média superior à média geral, mostrou comportamento oscilante nas diferentes avaliações $\left(\hat{\sigma}_{\mathrm{di}}^{2}>0\right.$ ), o que é um fato indesejável para a recomendação de cultivares. A cultivar IPA 206 e a linhagem TE 90-180-16F revelaram comportamento similar, entre si, em produtividade, estabilidade e previsibilidade em relação ao genótipo Balinha. Deve ser ressaltado que o IPA 206 é um genótipo larga- 
TABELA 1. Valores médios de seis caracteres avaliados em genótipos de caupi em regimes irrigado (RI) e sequeiro (RS), nos Municípios de Petrolina, PE, e Juazeiro, BA.

\begin{tabular}{llcccccr}
\hline Genótipo & Origem & \multicolumn{7}{c}{ Caráter $^{1}$} \\
\cline { 2 - 7 } & & DPM & PCG & COV & COS & NSV & CHP \\
\hline Santo Inácio (T1) - RI & Embrapa & 75 & 17,4 & 19,0 & Creme & 16 & 138 \\
IPA 206 (T2) - RI, RS & IPA, Pernambuco & 64 & 18,3 & 21,5 & Marrom & 13 & 84 \\
EPACE 10 - RI, RS & Epace, Ceará & 68 & 18,7 & 21,4 & Marrom & 14 & 64 \\
TE 90-180-26F - RI & Embrapa-CPAMN & 71 & 15,5 & 19,2 & Marrom & 14 & 147 \\
TE 90-180-16F - RI & Embrapa-CPAMN & 70 & 15,3 & 17,3 & Marrom & 13 & 144 \\
Balinha - RI, RS & Ouricuri, PE & 68 & 18.0 & 12,8 & Bege & 14 & 112 \\
EPACE 1 - RI & Epace, Ceará & 63 & 16,3 & 14,1 & Marrom & 13 & 69 \\
TE 86-75-17E2 - RI & Embrapa-CPAMN & 68 & 13,9 & 15,8 & Marrom & 12 & 138 \\
TE 90-179-2F - RI & Embrapa-CPAMN & 69 & 16,6 & 17,6 & Marrom & 13 & 188 \\
BR 17 Gurguéia - RI, RS & Embrapa-CPAMN & 65 & 11,7 & 15,9 & Marrom & 16 & 154 \\
BR 5 Cana Verde - RI & Embrapa & 71 & 15,1 & 12,2 & Creme & 12 & 32 \\
Vita 3 - RS & Embrapa & 71 & 20,0 & 20,0 & Vermelho & 14 & 47 \\
TE 90-180-6F - RS & Embrapa-CPAMN & 75 & 17,4 & 19,1 & Marrom & 13 & 153 \\
IT 86D-1010- RS & IITA, Nigéria & 67 & 16,5 & 14,9 & Marrom & 10 & 61 \\
TE 90-178-1F - RS & Embrapa-CPAMN & 75 & 16,5 & 17,8 & Marrom & 14 & 179 \\
IT 85F-2264 - RS & IITA, Nigéria & 70 & 13,5 & 13,1 & Marrom & 10 & 47 \\
EPACE 11 - RI, RS & Epace, Ceará & 70 & 19,0 & - & Creme & - & - \\
Canapu Precoce - RI, RS & Petrolina, PE & 71 & 21,0 & 17,6 & Marrom & 12 & 173 \\
\hline
\end{tabular}

${ }^{1}$ DPM: dias para a maturação; PCG: peso de 100 grãos (g); COV: comprimento da vagem (cm); COS: cor da semente; NSV: número de sementes/vagem; CHP: comprimento da haste principal $(\mathrm{cm})$.

TABELA 2. Parâmetros de estabilidade e adaptabilidade segundo o método de Eberhart \& Russell (1966) e estimativas de quadrados médios (QM) da análise conjunta, da produção de grãos em genótipos de caupi, avaliados em cinco experimentos irrigados, nos Municípios de Juazeiro, BA, e Petrolina, $\mathbf{P E}^{\mathbf{1}}$.

\begin{tabular}{|c|c|c|c|c|}
\hline \multirow[t]{2}{*}{ Genótipo } & \multicolumn{4}{|c|}{ Produção de grãos $(\mathrm{kg} / \mathrm{ha})$} \\
\hline & Média & $\hat{\beta}_{1 \mathrm{i}}$ & $\hat{\sigma}_{\mathrm{di}}^{2}$ & $\mathrm{R}^{2}(\%)$ \\
\hline & & $-0,1780$ & 63.566 & \\
\hline IPA & $1.604 \mathrm{abc}$ & $1,6288^{\mathrm{ns}}$ & & \\
\hline & & $0,6644^{\mathrm{ns}}$ & & \\
\hline TE & & 0,374 & -15.3 & 47 \\
\hline TE 9 & $a b c$ & 0,644 & -9.0 & 57,30 \\
\hline Balir & $\mathrm{a}$ & $0,9346^{\mathrm{ns}}$ & & \\
\hline EPA & $\mathrm{bc}$ & $2,2765^{* *}$ & 22.8 & 82,34 \\
\hline TE 8 & 1.5 & 1,330 & 38.0 & 54,26 \\
\hline TE 9 & 1.77 & $0,1456^{*}$ & 4.2 & 3,20 \\
\hline BR 17 Gurg & $1.694 \mathrm{ab}$ & $2,1788 * *$ & $27.230^{\mathrm{ns}}$ & 79,55 \\
\hline \multicolumn{5}{|c|}{$\begin{array}{l}{ }^{1} \text { Médias seguidas da mesma letra não diferem a } 5 \% \text { de probabilidade pelo } \\
\text { teste do DMS; C.V. (\%), 18; QM-Ambiente (A), } 1.193 .159^{* *} \text {; } \\
\text { QM-Genótipos (G), 469.830*; QM-A x G, 219.576**; QM-Bloco/Am- } \\
\text { biente, } 322.304^{* *} \text {; QM-Resíduo, 85.262; relação entre o maior QM e o } \\
\text { menor QM do resíduo, } 5 \text {. }\end{array}$} \\
\hline \multicolumn{5}{|c|}{$\begin{array}{l}\text { ns, }{ }^{*} e^{* *} \text { Não-significativo e significativo a } 1 \% \text { e } 5 \% \text { de probabilidade, res- } \\
\text { pectivamente, pelo teste t para o parâmetro } \hat{\beta}_{1 \mathrm{i}} \text { e pelo teste } \mathrm{F} \text { para o } \\
\text { parâmetro } \hat{\sigma}_{\mathrm{di}}^{2} \text {. }\end{array}$} \\
\hline
\end{tabular}

mente cultivado e recomendado na região, e está no mercado há quase dez anos.

Os parâmetros de adaptabilidade e estabilidade estimados segundo o método de Eberhart \& Russell (1966) e as estimativas dos quadrados médios dos genótipos avaliados em regime de sequeiro são apresentados na Tabela 3. Todos os quadrados médios apresentaram significância $(\mathrm{P}<0,01)$, incluindo a interação genótipo $\mathrm{x}$ ambiente. As principais alterações ocorridas nas áreas onde os experimentos foram conduzidos estão relacionadas com as oscilações pluviométricas entre anos e locais e as condições do tipo de solo; o experimento instalado no ano de 1998, na EEC, foi perdido, por causa do baixo índice pluviométrico ocorrido na região. As cultivares e linhagens desenvolvidas no Norte e Nordeste do Brasil apresentaram produções próximas ou acima da média geral do experimento, ao contrário dos genótipos IT 86D-1010 e IT 85F-2264, introduzidos da Nigéria, que tiveram os menores rendimentos. A cultivar EPACE 10, além de apresentar produção estatisticamente superior a IPA 206, BR 17 Gurguéia, Balinha, TE 90-180-6F e aos dois genótipos introduzidos da Nigéria, apresentou adaptabilidade especí- 
fica a ambientes favoráveis $\left(\hat{\beta}_{1 \mathrm{i}}>1\right)$, e boa estabilidade ante as mudanças de ambientes $\left(\hat{\sigma}_{\mathrm{di}}^{2}=0\right)$. Para as condições de sequeiro, talvez seja preferível um genótipo de adaptabilidade ampla $\left(\hat{\beta}_{1 \mathrm{i}}=1\right)$ e de cor aceitável pelos consumidores, como é o caso do TE 90-178-1F.

Na Tabela 4 são apresentados os parâmetros de adaptabilidade e estabilidade estimados segundo o método de Eberhart \& Russell (1966) e as estimativas dos quadrados médios de seis genótipos comuns aos dois ambientes. A EPACE 11, que teve sementes disponibilizadas no ano de 1997, e o Canapu Precoce, genótipo local, que passou a ser intensamente cultivado e a ter preço diferenciado no mercado, foram incluídos nas avaliações a partir do ano de 1997. Mais uma vez, observa-se interação significativa genótipo $\mathrm{x}$ ambiente $(\mathrm{P}<0,01)$, indicando, assim, que os genótipos revelaram respostas distintas nos diferentes ambientes. Os genótipos Balinha e Canapu

TABELA 3. Parâmetros de estabilidade e adaptabilidade segundo o método de Eberhart \& Russell (1966) e estimativas de quadrados médios da análise conjunta, da produção de grãos em genótipos de caupi, avaliados em cinco experimentos de sequeiro, nos Municípios de Juazeiro, BA, e Petrolina, $\mathbf{P E}^{\mathbf{1}}$.

\begin{tabular}{lccrc}
\hline \multirow{2}{*}{ Genótipo } & \multicolumn{4}{c}{ Produção de grãos (kg/ha) } \\
\cline { 2 - 5 } & Média & $\hat{\beta}_{1 \mathrm{i}}$ & \multicolumn{1}{c}{$\hat{\sigma}_{\mathrm{di}}^{2}$} & $\mathrm{R}^{2}$ \\
\hline IPA 206 & $1.087 \mathrm{bc}$ & $0,7133^{*}$ & $-5.443^{\mathrm{ns}}$ & 96,83 \\
BR 17 Gurguéia & $1.133 \mathrm{~b}$ & $0,8588^{\mathrm{ns}}$ & $9.986^{\mathrm{ns}}$ & 90,77 \\
EPACE 10 & $1.343 \mathrm{a}$ & $1,4501^{* *}$ & $-181^{\mathrm{ns}}$ & 98,29 \\
Balinha & $1.090 \mathrm{bc}$ & $1,0978^{\mathrm{ns}}$ & $-3.606^{\mathrm{ns}}$ & 98,08 \\
BR 5 Cana Verde & $1.253 \mathrm{ab}$ & $1,2821^{*}$ & $7.109^{\mathrm{ns}}$ & 96,24 \\
Vita 3 & $1.191 \mathrm{ab}$ & $1,1714^{\mathrm{ns}}$ & $-9.471^{\mathrm{ns}}$ & 99,89 \\
TE 90-180-6F & $1.064 \mathrm{bc}$ & $0,8431^{\mathrm{ns}}$ & $10.382^{\mathrm{ns}}$ & 90,28 \\
IT 86D-1010 & $905 \mathrm{~cd}$ & $1,0333^{\mathrm{ns}}$ & $322^{\mathrm{ns}}$ & 96,52 \\
TE 90-178-1F & $1.176 \mathrm{ab}$ & $1,0760^{\mathrm{ns}}$ & $4.203^{\mathrm{ns}}$ & 95,61 \\
IT 85F-2264 & $831 \mathrm{~d}$ & $0,4741^{* *}$ & $8.842^{\mathrm{ns}}$ & 76,08 \\
\hline
\end{tabular}

${ }^{1}$ Médias seguidas da mesma letra não diferem a $5 \%$ de probabilidade pelo teste do DMS; C.V. (\%), 18; QM-Ambiente (A), 7.936.206**; QM-Genótipos (G), 465.114**; QM-A x G, 104.712**; QM-Bloco/Ambiente, 1.789.879**; QM-Resíduo, 39.418; relação entre o maior QM e o menor QM do resíduo, 6.

ns, * e ** Não-significativo e significativo a $1 \%$ e $5 \%$ de probabilidade, respectivamente, pelo teste t para o parâmetro $\hat{\beta}_{1 \mathrm{i}}$ e pelo teste F para o parâmetro $\hat{\sigma}_{\mathrm{di}}^{2}$.
Precoce apresentaram adaptabilidade ampla $\left(\hat{\beta}_{1 \mathrm{i}}=1\right)$, e estabilidade às mudanças de ambientes ( $\hat{\sigma}_{\mathrm{di}}^{2}=0$ ), razão pela qual são cultivados e mantidos pelos produtores locais. Esses dois genótipos mostraram características semelhantes no tamanho do grão, no porte da planta e na susceptibilidade a algumas viroses, diferenciando-se principalmente na cor do grão. EPACE 11, além de apresentar adaptação ampla $\left(\hat{\beta}_{1 \mathrm{i}}=1\right)$ e estabilidade às mudanças de ambientes $\left(\hat{\sigma}_{\mathrm{di}}^{2}=0\right)$, teve produções estatisticamente superiores à IPA 206 e Canapu Precoce. Já a cultivar EPACE 10, apesar de boa produção de grãos, apresentou o inconveniente de pequena previsibilidade produtiva.

No geral, ocorreu forte interação genótipo x ambiente nas três análises efetuadas (Tabelas 1, 2 e 3), o que indica que os genótipos possuem desempenhos distintos quando cultivados em diferentes situações de manejo e épocas do ano, embora a distância entre os pontos extremos dos locais onde os experimentos foram conduzidos fosse inferior a $50 \mathrm{~km}$. Esses resultados indicam claramente a possibilidade de ex-

TABELA 4. Parâmetros de estabilidade e adaptabilidade segundo o método de Eberhart \& Russell (1966) e estimativas de quadrados médios da análise conjunta, da produção de grãos em genótipos de caupi, avaliados em seis experimentos em regime irrigado e de sequeiro, nos Municípios de Juazeiro, BA, e Petrolina, PE 1 .

\begin{tabular}{llccc}
\hline Genótipo & \multicolumn{4}{c}{ Produção de grãos (kg/ha) } \\
\cline { 2 - 5 } & Média & $\hat{\beta}_{1 \mathrm{i}}$ & $\hat{\sigma}_{\mathrm{di}}^{2}$ & $\mathrm{R}^{2}$ \\
\hline IPA 206 & $1225 \mathrm{bc}$ & $0,7886^{*}$ & $-1,2931^{\mathrm{ns}}$ & 96,42 \\
EPACE 10 & $1460 \mathrm{ab}$ & $1,0289^{\mathrm{ns}}$ & $7,1329^{* *}$ & 86,63 \\
Balinha & $1283 \mathrm{abc}$ & $1,1477^{\mathrm{ns}}$ & $0,2032^{\mathrm{ns}}$ & 96,48 \\
EPACE 11 & $1497 \mathrm{a}$ & $1,1713^{\mathrm{ns}}$ & $2,9705^{\mathrm{ns}}$ & 93,58 \\
Canapu Precoce & $1203 \mathrm{c}$ & $0,8870^{\mathrm{ns}}$ & $3,2519^{\mathrm{ns}}$ & 88,85 \\
BR 17 Gurguéia & $1290 \mathrm{abc}$ & $0,9766^{\mathrm{ns}}$ & $14,3899^{* *}$ & 77,03 \\
\hline
\end{tabular}

${ }^{1}$ Médias seguidas da mesma letra não diferem a $5 \%$ de probabilidade pelo teste do DMS; C.V. (\%), 18; QM-Ambiente (A), 1.153**; QM-Genótipos (G), 67 $7^{\text {ns: }}$ QM-A x G, 32**; QM-Bloco/Ambiente, 22*; QM-Resíduo, 11; relação entre o maior $\mathrm{QM}$ e o menor $\mathrm{QM}$ do resíduo, 5 .

ns, ${ }^{*} \mathrm{e}^{* *}$ Não-significativo e significativo a $1 \%$ e $5 \%$ de probabilidade, respectivamente, pelo teste $\mathrm{t}$ para o parâmetro $\hat{\beta}_{1 \mathrm{i}}$ e pelo teste $\mathrm{F}$ para o parâmetro $\hat{\sigma}_{\mathrm{di}}^{2}$. 
plorar satisfatoriamente a interação genótipo x ambiente, recomendando-se genótipos com ampla ou específica adaptação, tanto para áreas de sequeiro, como para áreas irrigadas, ao contrário de se fazerem recomendações generalizadas, baseadas em genótipos desenvolvidos para outras regiões. Entretanto, é preciso discutir a capacidade de produção e comercialização de sementes para pequenas áreas, quando se sabe que até os dias atuais os principais genótipos cultivados, principalmente nas áreas de sequeiro, são selecionados e mantidos pelos próprios agricultores.

Ênfase especial deve ser dada ao desenvolvimento de genótipos para áreas irrigadas, onde o genótipo Balinha apresentou médias e parâmetros de estabilidade e adaptabilidade mais favoráveis do que alguns genótipos desenvolvidos por instituições de pesquisa (Tabela 2) ou, ainda, estatisticamente similar ao genótipo EPACE 11 (Tabela 4). Deve ser mencionado que EPACE 11, lançada no ano de 1997, aparece como a primeira opção para o cultivo em áreas irrigadas no Nordeste.

A média de produção foi de $1.623,1.107$ e $1.324 \mathrm{~kg} / \mathrm{ha}$ de grãos, respectivamente, em áreas irrigadas, de sequeiro e no conjunto das duas situações (Tabelas 2, 3, e 4). Contudo as maiores produções de grãos foram de $1.779 \mathrm{~kg} / \mathrm{ha}$, do genótipo Balinha, em área irrigada (Tabela 2); de $1.343 \mathrm{~kg} / \mathrm{ha}$, da cultivar EPACE 10, em área de sequeiro, (Tabela 3) e de $1.497 \mathrm{~kg} / \mathrm{ha}$ de grãos na EPACE 11, no conjunto dos ambientes (Tabela 4). Este fato indica possibilidades concretas do desenvolvimento de genótipos produtivos nas condições não só da agricultura familiar, mas também na produção competitiva de grãos. Deve ser ressaltado que as condições de manejo adotadas nesses experimentos são similares às praticadas por alguns agricultores da região, diferenciando-se quanto à aplicação de agrotóxicos para o controle da cigarrinha-verde (Empoasca kraemeri).

\section{CONCLUSÕES}

1. A interação genótipo $x$ ambiente indica a necessidade do desenvolvimento de cultivares de caupi específicas para determinadas regiões e condições de cultivo.
2. O genótipo Balinha, selecionado e mantido por produtores, supera ou apresenta média de produção de grãos e parâmetros de estabilidade e adaptabilidade mais favoráveis em condições de regime irrigado, em comparação com cultivares tradicionais do Nordeste.

3. Para cultivo do caupi em regime de sequeiro, a cultivar EPACE 10 e a linhagem TE 90-180-1F apresentam comportamento e produção satisfatórios, superando genótipos locais, como Balinha, ou cultivares como IPA 206 e BR 17 Gurguéia.

\section{REFERÊNCIAS}

CRUZ, C.D. Programa Genes: aplicativo computacional em genética e estatística. Viçosa : UFV, 1997. 442p.

CRUZ, C.D.; REGAZZI, A.J. Modelos biométricos aplicados ao melhoramento genético. Viçosa : UFVImprensa Universitária, 1994. 390p

DUARTE, J.B.; ZIMMERMANN, M.J. de O. Adaptabilidade e estabilidade de rendimento de genótipos de feijoeiro comum. Pesquisa Agropecuária Brasileira, Brasília, v.29, n.1, p.25-32, jan. 1994.

EBERHART, S.A.; RUSSELL, W.A. Stability parameters for comparing varieties. Crop Science, Madison, v.6, p.36-40, 1966.

RAMALHO, M. A. P. Genética quantitativa em plantas autógamas: aplicações ao melhoramento do feijoeiro. Goiânia : Editora da UFG, 1993. 271p.

SAS INSTITUTE (Cary, Estados Unidos). SAS/STAT user's guide: version 6. 4.ed. Cary, 1989. v.1.

TEIXEIRA, S.M.; MAY, P.H.; SANTANA, A.C. de. Produção e importância econômica do caupi no Brasil. In: ARAUJO, J.P.P. de; WATT, E.E. (Org.). O caupi no Brasil. Brasília : IITA/Embrapa, 1988. p.99-136.

VENCOVSKY, R.; BARRIGA, P. Genética biométrica no fitomelhoramento. Ribeirão Preto : Sociedade Brasileira de Genética, 1992. 496p.

VENCOVSKY, R.; CRUZ, C.D. Comparação de métodos de correção do rendimento de parcelas com estandes variados. I. Dados simulados. Pesquisa Agropecuária Brasileira, Brasília, v.26, n.5, p.647-657, maio 1991. 